\title{
A situação das políticas de sustentabilidade brasileiras perante as metas de desenvolvimento do milênio da ONU no ano de 2008
}

\author{
The status of the Brazilian sustainability policies versus the UN millennium \\ development goals in 2008
Le situación des politiques brésilien du développement durabilité comparativement aux Objectifs du Millénaire de les Nations Unies en 2008

\section{La situación de las políticas de sostenibilidad brasileñas frente a las metas de Desarrollo de la ONU en 2008}

\author{
Paulo Henrique Gomes Antello e Silva* \\ (paulo.antello@ms.sebrae.com.br)
}

Recebido em 18/03/2013; revisado e aprovado em 27/07/2013; aceito em 10/08/2013

\begin{abstract}
Resumo: Este trabalho busca testar a atualização e o alinhamento das diretrizes políticas brasileiras quanto ao tema sustentabilidade. Para isso, toma o Projeto Metas do Milênio da Organização das Nações Unidas como modelo e contrasta à Agenda 21 Brasileira. A intenção é encontrar e propor possíveis diretrizes estratégicas a serem inseridas no modelo brasileiro.

Palavras-chaves: Políticas brasileiras de sustentabilidade. Agenda 21 Brasileira. Projeto do milênio. Comparativo. Abstract: This article tests the updating and the political strategic alignment of Brazilian policies in the theme of sustainability. To do that, it will take the Project Millennium development goals of the Organization of the United Nations as a model and compare with the Brazilian Agenda 21. The intention is to find and propose possible strategic guidelines to be added to the Brazilian model.

Key words: Brazilian Sustainability Policies. Brazilian Agenda 21. Millennium Project. Comparative

Resumen: Este articulo buscar chequear la actualización y el alineamiento de las directrices políticas brasileñas cuanto al tema de sustentabilidad. Para eso, toma el Proyecto Metas Del Milenio de La organización de las Naciones Unidas como un modelo y contrasta a la Agenda 21 Brasileña. La intención es encontrar y proponer posibles directrices estratégicas a ser añadidas al modelo Brasileño.

Palavras-clave: Políticas brasileñas de sustentabilidad. Agenda 21 Brasileña. Proyecto del milenio. Comparativo.

Résumé: Ce document vise à tester l'actualisation et les lignes directrices politiques brésiliens concernant la enjeu du développement durable alignement. Pour ce faire, prendre les Objectifs du Millénaire pour le développement du projet de l'Organisation des Nations Unies comme un modèle et les contrastes de l'Agenda 21 du Brésil. L'intention est de trouver et de proposer des orientations stratégiques qui pourraient être insérées dans le modèle brésilien. Mots-Clés: Polítiques bresilien du sustentabilite. Agenda 21 bresilien. Projet du milenaire; Comparatif.
\end{abstract}

\section{Introdução}

Em um momento de eminente crise internacional, a preocupação com os rumos da economia do sistema internacional, cada dia mais, volta à atenção da população mundial a possíveis soluções para a construção de fortes bases para a geração e manutenção do desenvolvimento. Em todas as partes do globo esse acontecimento vem trazendo à tona a importância do tema "Desenvolvimento Sustentável" na agenda internacional.

Segundo Merico (1996) a sustentabilidade é a capacidade da geração atual de atender suas necessidades. Porém, sem nunca por em risco a capacidade das gerações futuras em fazê-lo. Este trabalho buscará perceber as políticas que seguem esta linha de raciocínio e o peso de suas atuações na sociedade dos países. Percebendo tal inclinação é importante observar o comportamento dos países em desenvolvimento, em relação à sustentabilidade, suas metas e nas ações de curto prazo.

À luz dos pensamentos de Sachs (2002), que afirmava que o desenvolvimento econômico para os países em desenvolvimento poderia ser auxiliado se utilizasse padrões endógenos de desenvolvimento mais justo e de maior respeito ao ecossistema, este trabalho busca em contrastes com o exterior, oportunidades para os programas de sustentabilidade brasileiros.

Conforme Merico (1996) o subsistema econômico alcança os limites da biosfera,

\footnotetext{
* Serviço de Apoio às Micro e Pequenas Empresas de Mato Grosso do Sul (SEBRAE/MS), Campo Grande, MS, Brasil.
} 
sendo essa uma ameaça vigente, visto que a liquidação do capital natural ${ }^{1}$ para manutenção dos fluxos de recurso do capital manufaturado o levará ao colapso. Portanto, mostram-se como soluções únicas a países que buscam desenvolvimento de longo prazo, seguir estudos de sustentabilidade.

Visando delinear as principais características dos projetos de Sustentabilidade internacional, esclarecendo possíveis conexões e contrastes entre elas, com seus efeitos e desdobramentos com as comunidades diretamente envolvidas.

\section{Objetivo}

Considerando a perceptível virada do enfoque de desenvolvimento dos sistemas econômicos ao desenvolvimento sustentável, cujo debate mais aprofundado dos países se iniciou na Conferência das Nações Unidas para o Meio Ambiente e o Desenvolvimento (CNUMAD), também conhecida como ECO92, intensificando-se gradativamente no inicio do novo milênio, é de fundamental importância estudar o alinhamento do Brasil quanto a este novo conceito. Segundo Ferreira e Viola (1996, p. 319):

O sistema econômico, que é uma ferramenta da sociedade, não passa de um subsistema aberto do ecossistema, precisando dele vitalmente como fonte supridora de recursos e espaço onde faz lançamento dos dejetos resultantes das atividades produtivas e de consumo.

Portanto, é de vital importância para a sociedade saber qual o nível de comprometimento do Brasil e de seus critérios de desenvolvimento sustentável quando contrastado ao "Projeto Do Milênio" da Organização das Nações Unidas, por ser este um documento de ações voltadas ao desenvolvimento sustentável reconhecido internacionalmente e assinado por 170 lideres de países por todas as partes do globo.

\section{Metodologia}

Através de levantamento bibliográfico de estudos nacionais, internacionais e publicações que fundamentam o desenvolvimento do estudo. Os dois documentos que serão comparados, o Relatório 2008 do "Projeto do Milênio" das Nações Unidas e a "Agenda 21 Brasileira" do Governo Federal do Brasil. Serão também apresentados gráficos e depoimentos de autoridades de ambas as fontes, dando uma visão mais realista e prática da situação, que poderá ser visualizada no dia-a-dia dos interessados em tal trabalho, por serem dois projetos que ainda estão em andamento atualmente.

\section{Discussão}

O Brasil e seus objetivos e políticas de sustentabilidade. Segundo Winchester (2005), em documento emitido pela CEPAL (Comissão Econômica para a América Latina e o Caribe), na maioria dos países da América latina, a competência de criação das políticas de desenvolvimento sustentável é de responsabilidade ministerial, com exceção ao Peru e o Chile, onde tal responsabilidade cabe a um colegiado. O autor aponta ainda para alguns fatores de auxílio às práticas de sustentabilidade, como a vinculação econômica, que se trata de aliar interesses econômicos, recompensas monetárias ou abonos ficais às empresas ou pessoas que se utilizam delas.

Os objetivos de sustentabilidade estão listados no documento "Agenda 21 Brasileira" que leva tal nome por ser uma lista de 21 diretrizes a serem perseguidas pelas políticas brasileiras (BRASIL, 2003). Seguem relacionados abaixo os temas a que se referem e as diretrizes (Quadros 1-5):

\begin{tabular}{|l|l|}
\hline Objetivos & Diretrizes \\
\hline Objetivo 1 & Produção e consumo sustentáveis contra a cultura do desperdício. \\
\hline Objetivo 2 & Ecoeficiência e responsabilidade social das empresas. \\
\hline Objetivo 3 & Retomada do planejamento estratégico, infraestrutura e integração regional. \\
\hline Objetivo 4 & Energia renovável e a biomassa. \\
\hline Objetivo 5 & Informação e conhecimento para o desenvolvimento sustentável. \\
\hline
\end{tabular}

Quadro 1 - A economia da poupança na sociedade do conhecimento.

Fonte: Brasil (2003).

\footnotetext{
1 Entenda se por capital natural a terra e todo seu ecossistema originário, animal, vegetal e mineral.
} 
Trata-se da luta pelo fim da cultura do desperdício, mostrando as consequências dessa cultura em nível de exaustão das fontes de produção de matéria prima e também da poluição dos locais de despejo do lixo, o que auxiliaria na criação de uma sociedade sustentável.

Ao se falar de ecoeficiência e responsabilidade social das empresas, busca-se uma mudança no espírito empresarial brasileiro como a que ocorreu após a Eco-92, que teve resultados muito superiores ao esperado, além de preparar as empresas e empresários brasileiros para a inserção internacional, que já faz disso uma exigência.

A integração regional, a geração de infra-estrutura e o planejamento estratégico, são fatores chave para a sustentabilidade, visto que pode evitar desperdícios em logística, além de poder aproveitar melhor sinergias e os avanços nos transportes e comunicação, evitando poluição, especialmente nos grandes centros (BRASIL, 2003).
Quanto à produção de energia elétrica, a situação da sustentabilidade brasileira é confortável, pois a produção é eminentemente limpa, sendo 95\% hídrica. Porém como se evidenciou em 2001 a dependência de fatores climáticos pode ser fatal, além da do fato de que se evidenciou também no Brasil o único programa de larga escala de substituição de derivados do petróleo, o Pró-Àlcool. Também é valida a experiência com bio-combustíveis que além de ecologicamente corretos, ajudam na distribuição de renda, pois é uma oportunidade a famílias carentes (BRASIL, 2003).

Observada a recente expansão do conhecimento nas últimas décadas, é de alta prioridade que o Brasil se coloque a frente na produção científica, porém é também necessário que esse conhecimento seja convertido em inovação tecnológica e não somente produção cientifica. Todo cidadão deve ter acesso ao conhecimento, não dar este acesso é retirar um cidadão do mercado competitivo de trabalho (BRASIL, 2003).

\begin{tabular}{|l|l|}
\hline Objetivos & Diretrizes \\
\hline Objetivo 6 & Educação permanente para o trabalho e a vida. \\
\hline Objetivo 7 & $\begin{array}{l}\text { Promover a saúde e evitar a doença, democratizando o Sistema } \\
\text { Unico de Saúde (SUS). }\end{array}$ \\
\hline Objetivo 8 & Inclusão social e distribuição de renda. \\
\hline Objetivo 9 & Universalizar o saneamento ambiental protegendo o ambiente e a saúde. \\
\hline
\end{tabular}

Quadro 2 - Inclusão social para uma sociedade solidária.

Fonte: Brasil (2003).

Considerando que no período pesquisado trata-se da sociedade do conhecimento, todo cidadão deve ser educado para poder usufruir plenamente de suas potencialidades e poder atingir o desenvolvimento e melhor qualidade de vida. O Brasil possui um problema crônico na educação, e essa é a causa de quase $40 \%$ da pobreza (BRASIL, 2003).

Perseguir melhorias na saúde é atitude básica na busca pela sociedade sustentável. Os primeiros passos neste sentido podem ser desde a proteção ao consumidor até ao melhor controle de alimentos e remédios, além da mudança de hábitos culturais e de consumos como o tabaco ou a vida sedentária. Já no caso do SUS (Sistema Único de Saúde), o problema está vinculado à regulamentação na distribuição de verba, que acaba favorecendo os grandes polos em detrimento das pequenas cidades (BRASIL, 2003).

A má distribuição de renda é fator chave a ser combatido no Brasil, visto que $10 \%$ detêm $50 \%$ da riqueza e $50 \%$ detêm apenas $8 \%$. Tais padrões de distribuição de renda são eticamente inaceitáveis para considerações de justiça social e para a cidadania. Melhoras nos índices sociais são indispensáveis para o país se manter entre as 10 maiores economias do mundo (BRASIL, 2003).

Representativa parcela da população brasileira vive sem saneamento básico e coleta de esgoto, se considerar que cada real investido em saneamento básico significa $R \$ 5,00$ reais de economia em saúde, deve-se pensar em saneamento universal se estendendo além da área urbana atingindo também a zona rural (BRASIL, 2003). 


\begin{tabular}{|l|l|}
\hline Objetivos & Diretrizes \\
\hline Objetivo 10 & Gestão do espaço urbano e a autoridade metropolitana. \\
\hline Objetivo 11 & Desenvolvimento sustentável do Brasil rural. \\
\hline Objetivo 12 & Promoção da agricultura sustentável. \\
\hline Objetivo 13 & Promover a Agenda 21 Local e o desenvolvimento integrado e sustentável. \\
\hline Objetivo 14 & Implantar o transporte de massa e a mobilidade sustentável. \\
\hline
\end{tabular}

Quadro 3 - Estratégia para a sustentabilidade urbana e rural

Fonte: Brasil (2003).

Para uma melhor gestão do espaço urbano se deve buscar descentralizar as políticas de sustentabilidade escoradas na instância federal, distribuindo-as na instância local, buscando formar uma co-gestão local, que depende diretamente de uma sincronia entre seu poder e o poder federal e estadual (BRASIL, 2003).

Já no que se trata das áreas rurais, a agricultura mecanizada associada às grandes pastagens da pecuária extensiva, está ocorrendo o êxodo rural, enviando para as cidades mais trabalhadores do que ela suporta, o que gera favelas e criminalidade (BRASIL, 2003).

A ideia de sustentabilidade na agricultura se baseia no conceito de inovação tecnológica, buscando conservar cada vez mais os recursos naturais. Porém, por estar muito associada a indústria e serviços e também devido a cada ecossistema ser muito peculiar, é improvável que existam práticas de sustentabilidade a serem adotadas em massa (BRASIL, 2003).

Antecipando essa dificuldade, vários municípios brasileiros já haviam se antecipado ao lançamento da Agenda 21 Brasileira lançando projetos locais, que visavam atender as necessidades de sustentabilidade do município ou região, em 2008 já eram mais de duzentas agendas locais pelo Brasil todas extremamente bem colocadas de acordo com a região, alavancando vários projetos de sustentabilidade (BRASIL, 2003).

A economia de transporte, viabilizada pelo melhor planejamento de transportes em massa ou vias publicas busca não somente economizar dinheiro público e evitar a poluição gerada, mas também em economizar o stress desnecessário ao trabalhador, com isso gerando melhores desempenhos no trabalho ou como é conhecido tal soma de fatores, mobilidade sustentável (BRASIL, 2003).

\begin{tabular}{|l|l|}
\hline Objetivos & Diretrizes \\
\hline Objetivo 15 & Preservar a quantidade e melhorar a qualidade da água nas bacias hidrográficas \\
\hline Objetivo 16 & $\begin{array}{l}\text { Política florestal, controle do desmatamento e corredores de } \\
\text { biodiversidade }\end{array}$ \\
\hline
\end{tabular}

Quadro 4 - Recursos naturais estratégicos: água, biodiversidade e florestas

Fonte: Brasil (2003).

Para tratar-se de preservação de águas deve-se considerar que $15 \%$ das reservas de águas doces do mundo estão no Brasil, porém a principal motivação do objetivo é o fato da degradação de algumas das bacias hidrográficas brasileiras, como a do Rio São Francisco, ou de rios como o Tiete. Deve-se ter um cuidado maior ao gerir nossos recursos hídricos, para evitar problemas como a desertificação no Nordeste, poluição no Pantanal e pela preservação da Amazônia (BRASIL, 2003).
Considerado o país de maior biodiversidade do mundo, devido à extensão continua de seus biomas, o Brasil deve criar projeto pela preservação de suas florestas, para evitar que a devastação da Mata Atlântica se repita no Pantanal e na Amazônia, a criação de corredores de biodiversidade (áreas continuas de preservação) já é uma ideia em implementação. Deve-se também buscar o desmatamento zero e o inicio do reflorestamento de áreas devastadas (BRASIL, 2003). 


\begin{tabular}{|l|l|}
\hline Objetivos & Diretrizes \\
\hline Objetivo 17 & Descentralização e o pacto federativo: parcerias, consórcios e o poder local \\
\hline Objetivo 18 & Modernização do Estado: gestão ambiental e instrumentos econômicos. \\
\hline Objetivo 19 & Relações internacionais e governança global para o desenvolvimento sustentável. \\
\hline Objetivo 20 & Cultura cívica e novas identidades na sociedade da comunicação. \\
\hline Objetivo 21 & Pedagogia da sustentabilidade: ética e solidariedade. \\
\hline
\end{tabular}

Quadro 5 - Governança e ética para a promoção da sustentabilidade Fonte: Brasil (2003).

Com a Constituição Federal de 1988, ficou definida a descentralização fiscal, visando à melhor distribuição de recursos pelos municípios, visando igualá-los. O principal motivo disso é a crescente integração tecnológica, que não estava sendo acompanhada pelo governo federal, devido a distância dessa instância pública da sociedade civil. Portanto para aproximar o governo da população, transferiram-se alguns poderes ao município que atua em sintonia com o estado que por sua vez com o governo federal (BRASIL, 2003).

$O$ Estado brasileiro encontra-se muito carente de informações disponíveis aos governantes tanto devido à ausência de informação, quanto à ausência de comunicação entre os órgãos do governo. Deve-se buscar o aporte de recursos para a reorganização estrutural dos sistemas de gestão ambiental, buscando modernizá-lo para que se possa tomar atitudes menos intuitivas e cada vez mais bem fundadas (BRASIL, 2003).

No seu papel de país emergentes, o Brasil tem demonstrado extrema capacidade de se relacionar internacionalmente, devido à sua tradição diplomática, como se pode ver na Eco-92. Já no caso da governança global, é urgente que os países busquem se estabelecer para ganharem representatividade comercial, diminuindo barreiras e aumentando o intercâmbio científico e tecnológico, visando um melhor desenvolvimento sustentável (BRASIL, 2003).

Há uma cultura de integração dos povos e geração de uma nova identidade brasileira, miscigenada e avessa a preconceitos de gênero e raça. Por isso, considerando o baixo nível de educação das massas brasileiras, fica relegado aos meios de comunicação um papel importantíssimo de formar essa identidade e opiniões quanto a ela.

Para um desenvolvimento sustentável é necessário uma melhor regulamentação do que esta sendo exibido nas TVs e rádios, pois devido às horas de exposição, esses meios acabam por se tornar grandes meios de influência, que devem ser utilizados também para ajudar a criar essa identidade do cidadão brasileira e instruí-lo à sustentabilidade (BRASIL, 2003).

A pedagogia visa gerar um sentimento de universalidade, sobrepondo à modernidade técnica que veio a gerar uma desumanização da sociedade, por uma modernidade ética sobre a qual paira a interdependência dos seres humanos, das sociedades e de seu meio-ambiente, visando uma sociedade mais igualitária, justa e solidaria (BRASIL, 2003).

\section{O projeto do milênio da Organização das Nações Unidas}

Para melhor entender os resultados obtidos quanto às políticas de sustentabilidade brasileiras, este trabalho comparará o modelo brasileiro com o programa da ONU Millennium Development Goals (Metas de Desenvolvimento para o Milênio). Esse programa faz parte do Millennium Project (Projeto do Milênio), que foi criado em 2002, pelo Secretário Geral da ONU, para desenvolver um plano concreto de ações para alcançar as metas do milênio e assim diminuir a crescente pobreza mundial, fome e doenças que atingem bilhões de pessoas (ORGANIZAÇÃO DAS NAÇÕES UNIDAS, 2008a).

Segundo o Secretário Geral da ONU Ban Ki-moon, quanto às metas de desenvolvi- 
mento do milênio, erradicar a pobreza extrema continua sendo um dos desafios principais de nosso tempo e é a principal preocupação da comunidade internacional. Terminar esse flagelo irá exigir esforços combinados de todos os governos, sociedade civil, organizações e o setor privado, no contexto de uma parceria global mais efetiva para o desenvolvimento. As Metas de Desenvolvimento para o Milênio colocam os objetivos e os prazos, por meio dos quais o progresso na redução da pobreza, fome, doença e falta de moradia própria e exclusão - enquanto promovendo igualdade de gênero, saúde, educação e sustentabilidade - pode ser medido. Essas metas também caracterizam os direitos humanos básicos - o direito de cada pessoa no planeta à educação, saúde, moradia e segurança. Salienta ainda, que as metas são ambiciosas, porém factíveis e, junto à abrangente agenda da ONU, designam o curso dos esforços mundiais para aliviar a pobreza extrema até 2015 (ORGANIZAÇÃO DAS NAÇÕES UNIDAS, 2008a).

O Millennium Development Goals Report 2008 (Relatório das Metas de Desenvolvimento de 2008), desenvolvido pela Organização das Nações Unidas (2008b), sobre as metas voltadas a reestruturar situações de desequilíbrio social existente no mundo, apresenta os seguintes resultados:

A Primeira das metas é a de "Erradicar a pobreza extrema e a fome", que resume se em diminuir pela metade o número de pessoas vivendo abaixo de um dólar por dia até 2015. A pesar da alta dos preços de alimentos e commodities ocorrida no período que precedeu o ano de 2008 e que levará mais 100 milhões de pessoas à faixa de pobreza extrema, a meta ainda é alcançável.

A educação é o alvo da Segunda meta, que busca "Alcançar educação primária universal", a situação em 2006 era de 90\% das crianças mundiais matriculadas em escolas primárias, tendo o número de crianças sem acesso à educação caído de 103 milhões em 1999 para 73 milhões em 2006, tendo vários países desenvolvidos alcançado a meta da educação primária universal. A principal área com problemas na educação infantil é a África subsaariana com, em média, apenas $73 \%$ de crianças estudando, região do continente africano a sul do Deserto do Saara.

Com o enfoque na desigualdade de gê- nero, a Terceira meta da ONU é a "Promoção da igualdade de gênero e a potencialização da mulher". As mulheres estão tendo hoje muito mais oportunidade do que em qualquer período predecessor, o problema é que ainda hoje, os empregos oferecidos são instáveis e pagam menos à mulheres. Em países asiáticos e africanos também existe outro problema, as mulheres têm mais dificuldade em se matricularem e se manterem estudando. Já nos países mais desenvolvidos as mulheres têm ganhado espaço na sociedade e têm sido cada vez mais influentes na política, variando regionalmente, devido a culturas especificas.

A Quarta meta de desenvolvimento do milênio visa defender as crianças buscando "Diminuir a mortalidade infantil", pois pela primeira vez o número caiu abaixo de 10 milhões de crianças abaixo de cinco anos por ano. O grande alvo desta meta para ações futuras são, especialmente, a África e os países em desenvolvimento, visto que a primeira é responsável por metade das mortes no mundo e nos segundos a chance de óbito antes dos 5 anos é 13 vezes maior que em países do hemisfério norte.

Também voltada à mulher, a Quinta meta, busca "Melhorar a saúde materna", pois a taxa de mortalidade materna durante a gravidez, parto ou após seis semanas do parto ainda encontra-se inaceitavelmente alta na África e nos países em desenvolvimento, sendo na primeira uma chance a cada vinte e dois nascimentos, o que é discrepante quando comparado a um a cada sete mil e trezentos em regiões desenvolvidas. Nesse objetivo ainda se tem muito a fazer, pois a queda entre 1990 e 2005 foi de 1,1\% enquanto o necessário era que fosse de $5,5 \%$ para se atingir a meta.

Voltado à proteção da população em geral, a Sexta meta é "Combater AIDS, malária e outras doenças". O caso da AIDS é o mais grave, pois 7.500 são infectadas e 5.500 morrem todos os dias da doença. Graças à programas anti-HIV, o numero de pessoas contaminadas por ano diminuiu de 3 milhões em 2001 para 2,7 em 2007. Outro dado positivo já alcançado é o fato de hoje termos mais pessoas com o HIV no mundo, o que demonstra que os infectados estão vivendo mais, pois passou se de 29,5 milhões em 2001 para 33 milhões em 2007 sendo que grande parte destes estão na África subsaariana. 
O meio-ambiente também esta nas metas de desenvolvimento do milênio e encontra-se representado na penúltima e Sétima meta, "Garantir sustentabilidade ambiental". O desmatamento, o aquecimento global e a escassez de água potável são as três principais preocupações no controle do clima. Apesar de ser algo que atinge todo o mundo, um cuidado especial deve ser dado para áreas como a Oceania, Ártico, pequenas ilhas e grandes deltas da Ásia e especialmente na África, devido a baixa capacidade de resistência à desastre de sua população.

Por último, Oitava meta, tratando do lado econômico, deve-se buscar "Desenvolver uma parceria global na busca pelo desenvolvimento". Deve-se buscar aumentar as doações dos países do grupo dos desenvolvidos, para o grupo dos países menos desenvolvidos. Deve-se também buscar isentar mais tarifas de produtos originários de exportações de países menos desenvolvidos, se deve lidar mais compreensivamente com os débitos financeiros nacionais desse tipo de nação e buscar oferecer maior acesso a tecnologia e informação.

A Organização das Nações Unidas (2008b), diante do que apresenta o Relatório 2008 , conclui que as metas podem ser atingidas se forem dados, imediatamente, os passos necessários para se atingir os compromissos já feitos. Alcançar as metas para o desenvolvimento é, não somente vital para melhor construir uma vida mais saudável, melhor e mais decente para milhões de pessoas, mas também essencial para construir a paz e a segurança global duradoura.

\section{A situação do Brasil quanto às "Metas de Desenvolvimento para o Milênio" da Or- ganização das Nações Unidas}

Quando comparada às "Metas de Desenvolvimento para o Milênio", da ONU, a "Agenda 21 Brasileira" demonstrou ter varias semelhanças à este modelo internacional na busca do desenvolvimento sustentável. Percebe-se, portanto, a atualidade do projeto brasileiro e seu alinhamento às vertentes do pensamento moderno internacional, no que diz respeito à sustentabilidade.

Ao se explorar mais proximamente às metas percebe-se a existência de um paralelo entre os modelos. No caso da primeira meta do modelo da ONU - “Erradicar a pobreza e a fome extrema" - existe semelhança no caso do Objetivo 08 da Agenda 21 - "Inclusão Social e Distribuição de Renda". Ambas buscam uma maior igualdade de oportunidades para as pessoas menos favorecidas no que tange a pobreza e por consequência, a fome.

$\mathrm{Na}$ segunda meta da ONU, "Alcançar educação primária universal", percebe-se a busca de um fim comum da Agenda 21 Brasileira, em seu Objetivo 06, que coloca como meta a "Educação permanente para o trabalho e a vida". Fica clara a busca pela formação educacional da população, como forma de torná-la menos vulnerável e mais capacitada para o mercado de trabalho, gerando por consequência a inclusão social.

O primeiro caso de meta da ONU, não encontrada nas metas brasileiras foi a terceira a "Promoção da igualdade de gênero e a potencialização da mulher", visto que não existe nada neste sentido no modelo brasileiro. Considerando-se também o fato da meta número cinco "Melhorar a saúde materna" também não ser encontrado em nenhum dos tópicos da Agenda 21 Brasileira, pode-se perceber que existe uma carência de atenção na questão dos gêneros, mais especificamente na questão da mulher brasileira.

Conforme visto neste trabalho, o único objetivo do modelo brasileiro que mais se aproxima à necessidade de atenção com a maternidade, sugerida na meta número cinco da ONU, é o objetivo número sete da Agenda 21 Brasileira, "Promoção da saúde, evitar a doença e democratizar o SUS." Que no caso já atenderia a meta número quatro da ONU também que é "Diminuir a mortalidade infantil" e também seria o mais próximo da meta número seis da ONU "Combater AIDS, Malária e outras doenças".

Saindo um pouco do enfoque no ser humano e voltando suas atenções ao meioambiente, a meta número sete "Garantir sustentabilidade ambiental" esta muito bem representada na Agenda 21 Brasileira, nos objetivos um, dois, quatro, onze, doze, treze, quinze, dezesseis e vinte e um. Sendo estes, respectivamente: Produção e consumo sustentáveis contra a cultura do desperdício; Ecoeficiência e responsabilidade social das empresas; Energia renovável e a biomassa; 
Desenvolvimento sustentável do Brasil rural; Promoção da agricultura sustentável; Promover a "Agenda 21" Local e o desenvolvimento integrado e sustentável; Preservar a quantidade e melhorar a qualidade da água nas bacias hidrográficas; Política florestal, controle do desmatamento e corredores de biodiversidade e Pedagogia da sustentabilidade: ética e solidariedade.

A última meta de desenvolvimento para o milênio "Desenvolver uma parceria global na busca pelo desenvolvimento" é a única de enfoque econômico, que no caso brasileiro esta colocada também nos seguintes objetivos: Promover a Agenda 21 Local e o desenvolvimento integrado e sustentável (Objetivo 13); Relações internacionais e governança global para o desenvolvimento sustentável (Objetivo 17) e Pedagogia da sustentabilidade: ética e solidariedade (Objetivo 19). Mostrando total adequação do modelo brasileiro na vertente econômica.

Durante a comparação, deve se levar em conta a disparidade no numero de metas, visto que são oito (no Projeto do Milênio) contrapostas a vinte e uma (Agenda 21 Brasileira). Ainda assim, ao colocar lado a lado os dois projetos, pode-se analisar a adequação ou não do projeto brasileiro ao da ONU. A importância disso seria avaliar o grau de atualização do projeto brasileiro e de suas diretrizes políticas quando comparado a um projeto de sustentabilidade de Classe Mundial.

\section{Conclusão}

É importante que as políticas brasileiras sejam comparadas internacionalmente, para que possa ser trazido do exterior, modelos positivos que tenham viabilidade de serem inseridos na realidade nacional ou até mesmo local. Além deste motivo, também é importante para que possa ser percebido o grau de atualização das diretrizes políticas brasileiras.

Por ser a base do estudo, iniciou-se delineando as políticas brasileiras, para se poder, então, compará-las ao "Projeto do Milênio" da ONU. Ao iniciar a análise, percebeu-se o ser humano como centro das políticas de sustentabilidade brasileiras e que nos poucos momentos que fogem desse enfoque direto (como ao tratar dos assuntos referentes ao meio-ambiente, gestão do espaço rural e urbano, ou das relações internacionais e a governança global) o principal beneficiado destas ações continuam sendo o ser humano seja ele da geração da época em estudo (2008) ou subsequente.

O modelo brasileiro de busca à sustentabilidade, somado a toda a estrutura ao redor dele e a favor de colocá-lo em prática, poderia ser aprimorada se os bons exemplos que vêm do exterior fossem colocados em prática, ou pelo menos inseridos no projeto ou nas diretrizes políticas nacionais.

Percebe se, uma maturidade nas políticas públicas brasileiras, visto que, o país já tem sua "Agenda 21" estabelecida e no momento que foi comparada ao modelo internacional de desenvolvimento sustentável, percebeu se claramente que o modelo brasileiro se preocupa em inserir as diretrizes pré-estabelecidas em tal documento no que diz respeito à sustentabilidade.

Ao analisar o documento da ONU contraposto ao do Brasil percebe-se que algumas adições poderiam ser feitas. Existe carência na questão dos gêneros no projeto brasileiro, especialmente na defesa da questão da mulher e da saúde materna. Porém, considerando se que o Brasil é um país onde a desigualdade de gênero não é tão grave quanto nos países aos quais as políticas de gênero da ONU estão voltadas (Oriente Médio, Ásia e África), pode-se considerar que a falta deste tópico na agenda brasileira será sentido, porém não gravemente como em países aos quais se destinava.

Devido à atualidade do assunto e a prioridade que vem assumindo nas relações internacionais, percebe-se a necessidade de se abordar futuramente em outro trabalho, uma comparação das políticas Brasil à de grandes potências internacionais, visando disponibilizar ao povo brasileiro melhor Índice de Desenvolvimento Humano através do alinhamento das vertentes políticas brasileiras à de países que já alcançaram estes melhores níveis.

\section{Referências}

BRASIL. Ministério do Meio Ambiente. Agenda 21 Brasileira. Brasília, DF, 2003. Disponível em: <http:/ / www. mma.gov.br/index.php?ido=conteudo.monta\&idEstru tura=18\&idConteudo=908>. Acesso em: 30 jun. 2008.

FERREIRA, L. C.; VIOLA, E. Incertezas de sustentabilidade na globalização. Campinas: Unicamp, 1996. 
MERICO, L. F. K. Introdução à economia ecológica. Blumenau: Editora da FURB, 1996.

ORGANIZAÇÃO DAS NAÇÕES UNIDAS. Millennium Project. Disponível em: <http://www.unmillenniumproject.org/>. Acesso em: 31 ago. 2008a.

THE millennium development goals report 2008. Disponível em: <http://www.unmillenniumproject.org/>. Acesso em: 31 ago. 2008b.
SACHS, I. Caminhos pra o desenvolvimento sustentável. Rio de Janeiro: Garamond, 2002.

WINCHESTER, L. Sustainable human settlements development in Latin America and the Caribbean. Santiago: Comisión Económica para La América Latina y El Caribe, 2005. Medio ambiente y desarrollo, n. 99. Disponível em: <http:/ / www.eclac.org/publicaciones/xml/3/21543/ lcl2287i.pdf>. Acesso em: 31 ago. 2008. 
